\title{
Lógica y mística. Progreso espiritual y progreso filosófico
}

\author{
WALTER REDMOND \\ College of St. Thomas More, FortWorth, Texas \\ wredmond@texas.net
}

Resumen: Parece extraño conjugar mística y lógica. Los mismos místicos recalcan que, al alcanzar cierta madurez, experimentan a Dios por encima de la razón como a un "rayo de tinieblas". Además, algunos filósofos llegan a situar a Dios más allá de los entes o allende el ser, como vemos en la advertencia de Bonhoeffer de que no existe un dios que "existe" o en la reciente discusión sobre el "Dios sin ser". ¿Puede la lógica clásica dar cuenta de semejante avance filosófico o religioso? Para sugerir una respuesta, se examinan varias maneras de "cambiar de opinión" cotejadas con la dialéctica mística de Dionisio el Areopagita y con la doctrina de San Juan de la Cruz de que en la contemplación la noticia de Dios es confusa y oscura.

Palabras clave: lógica, mística, onto-teo-lógico, Dios sin ser, Dionisio el Areopagita, Juan de la Cruz

Abstract: It seems odd to link mysticism and logic. Mystics themselves stress that after coming to a certain maturity they experience God as a "dark ray" above reason. Also, philosophers may come to see God as beyond beings or being, as in Bonhoeffer's caution that an "existing" god does not exist, or in the current discussion of "God without being". Can classical logic cast light on such philosophical or religious progress? To suggest an answer, "changes of mind" are examined against the background of the mystical dialectic of Dionysius the Areopagite and St. John of the Cross' teaching that with the onset of contemplation the knowledge of God becomes confused and dark.

Key words: logic, mysticism, onto-theo-logical, God without being, Dionysius the Areopagite, John of the Cross

'Ākēn,
'attāh 'Ēl mistattēr,
'Ēlohê Yisrā'ēl, môšîa'

ISAÍAS

Everything is true

in a different sense,

A sense that would have

seemed meaningless before

T.S. ELIOT

*Isaías 45:15: "Eres en verdad un Dios escondido, oh Dios de Israel, Salvador"; Eliot: "Todo es verdadero en otro sentido, un sentido que antes habría parecido un sinsentido", The Family Reunion. A Play, parte 2, escena 2. 
Er muß diese Sätze überwinden, dann sieht er die Welt richtig

L. WitTGENSTEIN*

\section{¿Razón o tinieblas?}

Puede sonar raro juntar las palabras "lógica" y "mística", sobre todo hoy, cuando la espiritualidad no rara vez se toma como alivio de la razón, de la ciencia, de la lógica. En realidad, la filosofía misma a veces se ve como descanso de la razón, y a ciertas corrientes de filosofía, sobre todo en Francia, se les ha acusado de confundirse con la teología.

Hay, pues, problemas. ¿Qué diría el lógico de estas líneas de Dostoievski?:

Además,

si se me demostrara que Cristo está fuera de la verdad, y si la verdad realmente estuviera fuera de Cristo, yo quisiera quedarme más con Cristo que con la verdad. ${ }^{1}$

Esta afirmación es tan extraordinaria que sospechamos que Dostoievski ha batallado mucho para llegar a ella. Parece que ha superado ciertas actitudes convencionales, ha mudado de parecer religioso.

El cambio de opinión, en efecto, no es raro en la religión. No hace poco las etapas del "desarrollo de la fe" han sido codificadas, ${ }^{2}$ y —más al caso- los santos (y los guías de varias religiones) han observado que la vida espiritual no sólo cambia, sino que debe cambiar en ciertos rumbos: que ni siquiera el conocimiento de Dios es estático.

Seguramente hay un problema lógico aquí, pues cuando el homo religiosus madura, ¿la nueva conciencia que adquiere "supera" lo que antes conocía, creía, sentía? ¿Su fe anterior era de carbonero? ¿Se trata acaso de una ruptura cognoscitiva? También podemos hacer preguntas análogas ante las declaraciones de algunos filósofos recientes que hablan de Dios.

Otro problema lógico atañe a aquellos rumbos que los cambios deben tomar, pues, como Dostoievski, los místicos de la Iglesia han dicho que la madurez espiritual presupone cierto abandono de la razón. Tomás de Aquino, campeón del uso de la razón en la teología, confesó al final de

${ }^{*}$ L. Wittgenstein: "[Quien las entiende] debe superar estas proposiciones; entonces verá el mundo correctamente", Logisch-philosophische Abhandlung, n. 6.54.

${ }^{1}$ Carta 61 (a Vizine), 1854, Pis'ma, 1:1242.

${ }^{2}$ J.W. Fowler, Stages of Faith. 
su vida, después de una experiencia religiosa, que sus escritos no eran más que "paja", y que por la visión que tenemos de Dios en esta vida no vemos el "qué-cosa" de Dios, si bien "vemos lo que no es"; aún más, agrega,

cuanto más perfectamente conocemos a Dios en esta vida, tanto más entendemos que está más allá de todo lo que en el entendimiento se comprende. ${ }^{3}$

En su Peri tēs mystikēs theologias, Dionisio el Areopagita expresó la gran paradoja de la teología apofática: la luz divina ilumina al hombre en la oscuridad. Anhelaba llegar

a la cumbre más alta de la escritura mística, donde los misterios de la teología - simples, absolutos, inmutables-

están escondidos en la superbrillante niebla de silencio. ${ }^{4}$

En el siglo XIV, su anónimo discípulo inglés traducirá esta expresión, ho tès sigès gnophos, como "nube" en su obra The Cloud of Unknowing. Dionisio aconsejó así a su discípulo Timoteo (a quien dirigió el Peri tēs mystikēs theologias):

empeñado en la contemplación mística, abandona

tanto la sensación como la función del entendimiento, todo lo sentido y lo entendido,

a fin de que subas (hasta donde sea posible)

a la unión con aquél que está sobre la esencia y la ciencia;

pues, remoto de todo, libre de todo,

serás elevado a aquel sobrenatural

rayo de tiniebla divina. ${ }^{5}$

${ }^{3}$ Summa Theologica, 2-2:8:7: "per quam, etsi non videamus de Deo quid est, videmus tamen quid non est; et tanto in hac vita Deum perfectius cognoscimus, quanto magis intelligimus Eum excedere quidquid intellectu comprehenditur"; también 1:12:7. Véase S. Tugwell, editor y traductor, Albert and Thomas. Selected Writings, pp. 265-267.

${ }^{4}$ Peri tēs mystikēs theologias, 1:1. Probablemente se trata de un monje católico que vivió alrededor del año 500; se llama también "Pseudo-Dionisio" por confusión con el Dionisio que San Pablo conoció en el Areópago cuando, como F. Nietzsche, hablaba sobre el "Agnostōo ${ }_{i}$ Theō $_{i}$ (el Dios desconocido; Hechos, 17:34, "Dem unbekannten Gott”).

${ }^{5}$ Ibid. 
Esta frase, hè tou skotous aktis, será el "rayo de tiniebla" de San Juan de la Cruz.

San Buenaventura, tras citar estas palabras de Dionisio, dijo que si queremos saber cómo ha de ser este ascenso, debemos pedir

la gracia, no la doctrina,

el deseo, no el entendimiento,

el gemido de la oración, no el celo de la lectura,

el Esposo, no el maestro,

Dios, no el hombre,

la oscuridad, no la claridad,

no la luz sino el fuego... ${ }^{6}$

El autor del Cloud of Unknowing veía el gnophos de Dionisio, una niebla, entre Dios y nosotros, y advirtió a su discípulo que

esta oscuridad, esta nube entre ti y tu Dios, quedará

e impedirá

—hagas lo que hagas-,

que lo veas claramente en tu razón

por la luz del entendimiento

y que lo sientas en tu afecto

en la dulzura del amor. ${ }^{7}$

Juan de la Cruz encontró a Dios en la noche, y equiparó esta aktis (rayo) de Dionisio con la contemplación (Aristóteles señaló que la dificultad de encontrar la verdad se debe no sólo al objeto, sino a la razón):

Y de aquí es que la contemplación por la cual el entendimiento tiene más alta noticia de Dios llaman "teología mística", que quiere decir sabiduría

${ }^{6}$ Itinerarium mentis in Deum, 7:5-6: "Si autem quaeras quomodo haec fiant, interroga: gratiam, non doctrinam, desiderium, non intellectum, gemitum orationis, non studium lectionis, sponsum, non magistrum, Deum, non hominem, caliginem, non claritatem, non lucem sed ignem..."

${ }^{7}$ Anónimo, The Cloud of Unknowing, cap. 3: "This darkness and this cloud is, howsoever thou dost, betwixt thee and thy God, and hinders thee that thou mayst not see him clearly by light of understanding in thy reason nor feel him in sweetness of love in thine affection." El autor también tradujo la teología mística de Dionisio al inglés. 
de Dios secreta, porque es secreta al mismo entendimiento que la recibe; y por eso la llama san Dionisio "rayo de tiniebla". ${ }^{8}$

Juan, en efecto, nos ofrece una epistemología espiritual. El entendimiento, explica, adquiere el conocimiento tanto por vía natural como por vía sobrenatural. La natural abarca todo lo que el entendimiento conoce a través de los sentidos o por sí mismo; el objeto del conocimiento sobrenatural es todo lo que "se da al entendimiento sobre su capacidad natural". 9 Las "noticias sobrenaturales" pueden ser corporales (recibidas mediante la sensación o en la imaginación) o espirituales. Las "noticias e inteligencias" espirituales son a su vez o "distintas y particulares" (los fenómenos "extraordinarios", como las visiones y revelaciones) o "confusas, oscuras y generales". ${ }^{10}$ Ahora bien, agrega:

${ }^{8}$ Subida del Monte Carmelo, 2:8:6 (véase infra); Aristóteles, Metaphysica, 993b9ss. Véase también Juan de la Cruz, Noche oscura, 2:5:3. "Y no se ha de entender que esto que el alma entiende, porque sea sustancia desnuda (como habemos dicho), sea la perfecta y clara fruición como en el cielo, porque, aunque es desnuda de accidentes, no es por esto clara, sino oscura, porque es contemplación, la cual en esta vida, como dice san Dionisio, es rayo de tiniebla" (Cántico espiritual, B, estrofas 14-15:16), etc. Juan, recordando la doctrina aristotélica de que el entendimiento difícilmente atañe las verdades manifiestas ("como los ojos del murciélago la luz"), explica por qué la lumbre divina se llama "noche oscura": "Es por la alteza de la sabiduría divina, que excede al talento del alma, y en esta manera le es tiniebla [...] De donde cuando esta divina luz de contemplación embiste en el alma que aún no está ilustrada totalmente, le hace tinieblas espirituales, porque no sólo la excede, pero también la priva y oscurece el acto de su inteligencia natural" (Noche oscura, 2:5:2,3).

9 “[P]ara que luego por su orden más distintamente vayamos enderezando en [las aprehensiones] al entendimiento en la noche y oscuridad de la fe [...] Es, pues, de saber que por dos vías puede el entendimiento recibir noticias y inteligencias; la una es natural y la otra sobrenatural. La natural es todo aquello que el entendimiento puede entender, ahora por vía de los sentidos corporales, ahora por sí mismo. La sobrenatural es todo aquello que se da al entendimiento sobre su capacidad y habilidad natural" (Subida..., 2:10:1, 2).

10 "Destas noticias sobrenaturales unas son corporales, otras son espirituales. [Las] corporales son en dos maneras: unas que por vía de los sentidos corporales exteriores las recibe, otras por vía de los sentidos corporales interiores, en que se comprende todo lo que la imaginación puede comprehender, fingir y fabricar" (Subida..., 2:10:3). "Las [noticias e inteligencias] espirituales son también en dos maneras: unas distintas y particulares, y otra es confusa, oscura y general. Entre las distintas y particulares entran cuatro maneras de aprehensiones particulares, que se comunican al espíritu no mediante algún sentido corporal, y son: visiones, revelaciones, locuciones y sentimientos espirituales" (Subida..., 2:10:4). 
La inteligencia oscura y general está en una sola, que es la contemplación que se da en fe. En ésta habemos de poner el alma, encaminándola a ella (por todas esotras, comenzando por las primeras, y desnudándola de ellas). ${ }^{11}$

Para el Doctor Místico, pues, la persona espiritualmente comprometida avanza hacia la contemplación confusa, oscura, general.

\section{Superaciones filosóficas}

Notamos también en la filosofía teológica cierto "progreso intelectual" que, si bien es análogo a esta experiencia de los santos, encierra otra problemática. Blaise Pascal contrastó el "Dios de los filósofos" con el "Dios de Abraham, Isaac y Jacob" —claro, en menoscabo del Dios de los filósofos. ${ }^{12}$ Martín Heidegger declaró que al dios de la filosofía, a quien nombra "Causa sui" (causa de sí mismo), "el hombre no le puede orar ni sacrificar"; ante este dios tampoco "puede caer de rodillas por reverencia, ni puede tocar y bailar". ${ }^{13}$ Recordemos entre paréntesis que Santo Tomás de Aquino negó que "Causa sui" fuera un nombre de Dios:

pues en este caso una cosa sería la causa de sí misma, y una cosa se produciría a sí misma en el ser, lo cual es imposible. ${ }^{14}$

Sea como sea, Heidegger evidentemente ambiciona ir más allá de la teología filosófica vulgar. Algunos creerán que el reciente filósofo de la religión Jean-Luc Marion dio el paso definitivo cuando calificó de "idólatras" a Tomás de Aquino y a otros teólogos por hablar de Dios como "siendo". ${ }^{15}$ Manuel Levinas deja atrás a toda la racionalidad occidental al reconocer la significación ética de Dios como el Otro. El famoso dicho del pastor evangélico Dietrich Bonhoeffer, de que no se da

${ }^{11}$ Subida..., 2:10:4; las palabras puestas entre paréntesis se encuentran en el códice de Alba.

${ }^{12}$ Pensées, n. 449.

13 "Die onto-theo-logische Verfassung der Metaphysik", p. 70: "Dies ist die Ursache als die Causa sui. So lautet der sachgerechte Name für den Gott in der Philosophie. Zu diesem Gott kann der Mensch weder beten, noch kann er ihm opfern. Vor der Causa sui kann der Mensch weder aus Scheu ins Knie fallen, noch kann er vor diesem Gott musizieren und tanzen."

${ }^{14}$ De ente et essentia, 4:130: "quia sic aliqua res esset causa sui ipsius et aliqua res se ipsam in esse produceret; quod est impossibile".

${ }^{15}$ Dieu sans l'être. Hors-texte; se retracta parcialmente en el prefacio a la edición inglesa, God without Being. Hors-texte, p. xxiii. 
un dios que "se da" (entre comillas), implica que el darse-sin-comillas es una actitud más sofisticada de hablar de Dios. ${ }^{16}$ Estos cambios de parecer se conciben como "avances". Hay muchos más ejemplos: el teólogo Karl Barth, cuando una vez llamó "Anticristo" a la analogia entis de Santo Tomás, Kierkegaard cuando ridiculizó los argumentos de la existencia de Dios, Kant cuando dijo que Dios no es asequible a la razón sin-más. Siempre he sospechado que los teólogos que con tanto afán colocan a Dios allende la razón están haciendo una apologética clandestina, pues si su religión está por encima de la razón, está a salvo de la razón. La línea divisoria entre esta apologética irracionalista y la tradición apofática puede ser tenue.

\section{La lógica y el cambio de opinión}

¿La razón, pues, debería destituirse in divinis, junto con su lógica? ¿O no se dará más bien "otra razón" más adecuada, tal vez una "lógica no occidental" (como el teólogo alemán Hans Küng sugirió)? Por otro lado, tal supresión de la lógica podría sorprender a Juan de la Cruz y al autor del Cloud, para quienes no sería fácil explicarse qué cosa sería una lógica no occidental. En todo caso, la vida espiritual, según tradiciones católicas, encierra no sólo la novedad, sino también la estabilidad. Por cierto, hay "vías", "grados", "etapas", "estadios" —aun caídas, altibajos-, pero también hay crecimiento orgánico. Por lo tanto podemos preguntarnos si la lógica tradicional es compatible, y cómo lo es, con el avance espiritual e intelectual.

Echemos un vistazo, pues, desde el punto de vista lógico, sobre cómo cambiamos de opinión. Por supuesto, podemos simplemente negar lo que creíamos antes. Ana, por ejemplo, antes creía que las ballenas eran peces, pero ahora sabe que son mamíferos. Su primera creencia contradice su nueva opinión, y si le preguntamos si antes estaba equivocada contestará que sí.

Pero hay maneras más sutiles de mudar de parecer. Digamos que Ana, antes de aprender que las ballenas son mamíferos, dijo a su hijito: "las ballenas viven en el mar". Si ahora le preguntamos si se equivocó antes, dirá que no, y explicará:

Claro que yo entonces no sabía que las ballenas son mamíferos, pero ni pensaba en eso; sólo quería decir que las ballenas son animales acuáticos.

${ }^{16}$ Bonhoeffer: "Einen Gott, den 'es gibt', gibt es nicht" (Akt und Sein, Transzendentalphilosophie und Ontologie in der systematischen Theologie, p. 94). 
Ana puede ver su cambio de opinión como un proceso de desambiguación de su primer concepto vago e indistinto. Su progreso, pues, consta de tres proposiciones que no se contradicen:

creencia anterior

(1) las ballenas viven en el mar

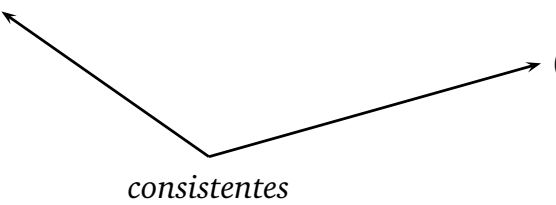

creencias posteriores

(2) las ballenas no son peces (3) las ballenas (que son mamíferos) viven en el $\operatorname{mar}^{17}$

El Dios que "se da" y el Dios que se da

Ahora supongamos que Ana ha creído en Dios desde niña, pero después de leer en Freud que Dios no existe (porque la religión es una neurosis obsesiva debida al complejo de Edipo de personas ansiosas que necesitan una figura paterna), se declara atea. ${ }^{18}$ "Dios existe" contradice "Dios no existe", y Ana niega su teísmo anterior. ${ }^{19}$

Pero digamos que en vez de Freud, Ana lee este dicho de Bonhoeffer:

un dios que "se da" no se da,

y sospecha que su concepto anterior de Dios ha sido algo superficial. Con todo, no cree que era atea antes de leer a Bonhoeffer. Puede reflexionar así:

Si el darse-entre-comillas indica cierta concepción defectuosa del ser divino - como si Dios fuera como son las cosas creadas-, hay que rechazarla. Y debo aceptar el darse-sin-comillas que parece indicar un sentido aceptable.

${ }^{17}$ He aquí una interpretación (no la única) del progreso, donde " $B x$ " significa que $x$ es ballena, " $V x$ " que $x$ vive en el mar, "Px" que $x$ es pez y " $M x$ " que $x$ es mamífero: (1) $\forall x[B x>V x]$, (2) $\forall x[B x>\sim P x]$, (3) $\forall x[B x>[M x \& V x]]$. Cada proposición es verdadera, y (3) implica (1). Evidentemente, Ana no tiene que ser consciente de tales relaciones; Jaako Hintikka dio el sentido en Knowledge and Belief. An Introduction to the Logic of the Two Notions: somos capaces de aceptar las consecuencias lógicas de nuestro discurso cuando se nos señalan.

${ }^{18}$ Die Zukunft einer Illusion, cap. 8.

${ }^{19}$ La misma contradicción, en sentido contrario, aparece en el paso del ateísmo al teísmo, como en la "conversión". 
En efecto, los filósofos teológicos, hoy como en el pasado, se han esforzado por especificar el derecho con que podemos hacer afirmaciones correctas de Dios. Las explicaciones tradicionales más familiares son las de Santo Tomás y de Juan Duns Escoto, ellas mismas interpretadas de varias maneras. Según Escoto, atribuimos a Dios el ser y el ser-así de un modo especial y único: infinito; en cambio, la noción tomista de la analogia entis no supone ningún aspecto unívoco del ser que abarque a Dios y creaturas.

Heidegger acusó a estos pensadores —en realidad, a todos los filósofos después de Sócrates- de hablar de manera "ontoteológica" de Dios. Por cierto, Hans Urs von Balthasar, el conocido teólogo suizo, vio la noción tomista del ipsius esse subsistentis como un kairon (o viraje) en la historia intelectual, precisamente porque Tomás reconoció la "diferencia ontológica" de Heidegger entre Sein y Seiendes, entre el ser y lo que es. Pero, más recientemente, el filósofo inglés Anthony Kenny calificó de "sofisma y falacia" el axioma tomista de la sencillez del ser divino. Y, por otro lado, existe en este momento una animada discusión, ya más allá de Heidegger, acerca de "l'Autrui" (el "Otro") de Levinas y el "Dieu sans l'être" (Dios sin ser) de Marion, quien se muestra "indiferente" a la diferencia ontológica. ${ }^{20}$ Marion incluso tacha el nombre divino ("Dieu") para

indicar el límite de las tentaciones, conscientes o ingenuas, a blasfemar lo impensable en un ídolo [...] Tachamos el nombre de Dios- sólo para poner de manifiesto (a nosotros mismos, claro), que lo impensable de él satura nuestro pensamiento, desde el comienzo mismo y para siempre. ${ }^{21}$

Haré uso de este dispositivo tipográfico de Marion para indicar en general algún sentido aceptable de nuestro lenguaje en torno al Numen. Y usaré las comillas de Bonhoeffer para significar un sentido inaceptable. La proposición de Bonhoeffer, pues, se escribiría así:

un dios que "se da" no se da,

${ }^{20}$ Véanse Fergus Kerr, After Aquinas. Versions of Thomism, p. 73, y Derek J. Morrow, "Aquinas, Marion, Analogy, and Esse: A Phenomenology of the Divine Names?" $\mathrm{y}$ "Aquinas According to the Horizon of Distance: Jean-Luc Marion's Phenomenological Reading of Thomistic Analogy", inédito.

${ }^{21}$ Usa la cruz de San Andrés, la cual "monte leur borne aux tentations, conscientes ou naïves, de blasphémer à l'impensable en une idole [... ] Nous ne raturons le nom de Dieu que pour nous manifester, à nous-mêmes bien sûr, que son impensable sature notre pensée- dès l'origine, et à jamais" (Dieu sans l'être, pp. 72-73). 
y el progreso de Ana aparecería así:

creencia anterior

Dios se da creencias posteriores

Dios no "se da"

Dios se da-

Ana puede también hacer un progreso en torno a los atributos divinos ("bueno", "amor", "don"... ). Por ejemplo, después de leer en Santo Tomás que

cuando se dice "Dios es bueno", el sentido no es que Dios es la causa de la bondad ni que Dios no es malo, sino que lo que llamamos bondad en las creaturas preexiste en Dios y en efecto de una manera más alta,

puede cambiar de parecer en este sentido:

Dios es bueno

Dios es buene: ${ }^{22}$

Dios no es "bueno"

La forma de estas proposiciones es distinta del caso de las ballenas, pero tampoco es necesario suponer aquí una relación contradictoria entre ellas. Ana no tiene que negar su creencia (o fe) anterior cuando adquiere una nueva actitud.

\section{El derecho a callar acerca de Dios}

Sea lo que fuere de estas controversias filosóficas, quiero usar la letra griega phi $(\varphi)$ para distinguir formalmente entre:

- cualquier manera inapropiada (entrecomillada: " $\varphi$ ") de hablar de Dios (nombrable, pensable, antropomórfica, ontoteológica, ontológica, metafísica, conceptual, cognitiva, objetivante, idolátrica, como ser, ente, cosa...), y

22 “Cum igitur dicitur 'Deus est bonus', non est sensus Deus est causa bonitatis vel Deus non est malus, sed est sensus: id quod bonitatem dicimus in creaturis praeexsistit in Deo et hoc quidem secundum modum altiorem" (Summa Theologica, 1:13:2). Nota también: "Non enim bonitas vel humanitas significantur in actu nisi prout significamus eam esse", pero "non sit aliud in [Deo] essentia quam suum esse" (Summa Theologica, 1:3:4).

Diánoia, vol. LIV, no. 62 (mayo 2009). 
- cualquier manera aceptable (tachada: $\varphi$ ) de hablar de Dios (como ser, no ser, amor, bien, donación, Otro, nada...).

En absoluto digo que los juicios de tales filósofos en torno a estas expresiones sean comprensibles ni mucho menos verdaderos; sólo digo que si una manera de hablar de Dios es verdadera, es "tachada"; si no, es "entrecomillada". Abrevio el esquema de la siguiente manera, donde la letra $\varphi$ hace las veces de cualesquiera estados de cosas apropiados:

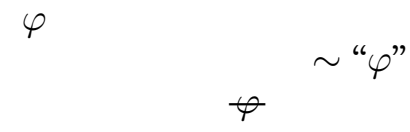

Es menester suponer, pienso yo, la posibilidad de que el móvil detrás del ascenso místico abarque elementos esencialmente distintos de las revisiones y condenaciones que encontramos en estos filósofos, expertos en la cuestión de Dios. Es relevante aquí el problema de quién - $\mathrm{y}$ por qué uno- tiene el derecho a hablar de Dios. ¿Por qué ciertos filósofos - aunque no aquellos pensadores a quienes desprecian- pueden discurrir correctamente sobre Dios?

En realidad, se ha criticado a Heidegger y Levinas recientemente por dar la impresión de gozar de un acceso privilegiado a su Sein (ser) o a su Autrui, una entrada privada, subrepticia, que suprime la "democracia" del diálogo filosófico; además, la ética de Levinas se ha calificado de "criptoteología". ${ }^{23}$ Y se ha señalado la ambigüedad del "penser Dieu" de Marion, por confundir los tres tipos del conocimiento de Dios que Edith Stein, por ejemplo, distingue cuidadosamente: (1) natural (la argumentación lógica), (2) revelado (la fe) y (3) sobrenatural (la contemplación). ${ }^{24}$ Pues Marion parece referirse al conocimiento natural cuando habla de Dios como Causa sui, a la fe cuando llama a Dios "amor" y a la experiencia sobrenatural cuando sugiere que el pensar a Dios es como "contemplación".

Mas es fácil rechazar las afirmaciones supuestamente defectuosas en torno a Dios. "Les systèmes sont vrais dans se qu'ils affirment" dice

${ }^{23}$ Referencias en Richard Wolin, "Heidegger Made Kosher", pp. 23-30. Recuerda el uso secularizado de la Biblia por el "Papa Rojo", Ernst Bloch (p.ej., en Das Prinzip Hoffnung), o la "espiritualidad sin Dios" de André Comte-Sponville, L'Esprit de l'athéisme.

${ }^{24}$ Antonio Calcagno: "God and the Caducity of Being: Jean-Luc Marion and Edith Stein on Thinking God", pp. 4-5; Stein, "Ways to Know God", Erkenntnis und Glaube, pp. 65-127, trad. W. Redmond, Knowledge and Faith, pp. 83-134. 
Leibniz, "et faux dans ce qu'ils nient." 25 A estos filósofos que niegan sin ambages, les ha resultado difícil afirmar; se quedan "entre comillas" y por ende hors de combat. Quizá Pascal tenía razón cuando habló despectivamente de los filósofos en su frase "el dios de los filósofos". ¿Quién, pues, tiene el derecho a callar?

\section{La dialéctica mística}

Regresemos ahora a la tradición espiritual. Dionisio, en efecto, hace destacar la importancia de ir más allá de las negaciones cuando presentó el esquema del progreso espiritual que iba a ser paradigmático en la espiritualidad y en la teología de la cristiandad oriental y occidental (también en el idealismo alemán). En el contexto de la theologia, o "Palabra de Dios", reconoció tres fases:

1) thesis ("posición") - kataphasis ("afirmación"): la vía (o "teología") positiva;

2) aphairesis ("remoción") - apophasis ("negación”): la vía negativa;

3) "hyper" (allende la kataphasis y la apophasis): la vía "superlativa". ${ }^{26}$

Describe una "dialéctica" en que su discípulo Timoteo aprende, desaprende y reaprende, reconociendo a Dios, por ejemplo, como siendo, como no-siendo, y como "ni uno ni otro":

thesis: kataphasis

Dios como ōn (siendo)

(antítesis) aphairesis: apophasis Dios como ouk ōn (no siendo)

(síntesis) "hyper"

Dios como oude ti tōn ouk ontōn

oude ti tōn ontōn (ni siendo ni no siendo),

o al pie de la letra: "ni nada de lo que no es ni nada de lo que es".

25 "Los sistemas son verdaderos en lo que afirman y falsos en lo que niegan", carta a Nicolás Remond, enero, 1714, Philosophische Schriften, vol. 3, p. 604.

${ }^{26}$ Dionisio usa la palabra thesis aquí. Para expresar la inteligencia que trasciende las anteriores, emplea la partícula hyper como preposición ("sobre", "allende"...), adverbio ("arriba", "más allá"...) o prefijo ("super-"...). 
Dionisio insiste en que hay que ir más allá de las afirmaciones y negaciones:

Tampoco hay que considerar que las negaciones sean contrarias a las afirmaciones;

sino que [la Causa de todo] sea muy anterior, [... ]

tanto sobre toda remoción

como sobre toda posición. ${ }^{27}$

Y dice de la pantōn Aitia, la Causa de todo:

ni la posición ni la remoción es universal, sino que cuando ponemos y removemos lo que está detrás de ella, a ella misma ni ponemos ni removemos,

y ofrece esta razón:

tanto la Causa de todo, perfecta y sencilla, está encima de cualquier posición,

como la sublimidad del que está simplemente separado de todo, está encima de cualquier remoción y más allá de las totalidades. ${ }^{28}$

El mismo marco formal sugerido antes representaría la dialéctica de Dionisio:

${ }^{27}$ Peri tēs mystikēs theologias, cap. 1:2: "Deon ep' autē $\bar{i}_{i}$ kai pasas tas tōn ontōn tithenai kai kataphaskein theseis hōs pantōn aitia $i$, kai pasas autas kyriōteron apophaskein, hōs hyper panta hyperousē $\bar{i}_{i}$, kai mē oiesthai tas apophaseis antikeimenas einai tais kataphasesin, alla poly proteron autēn hyper tas sterēseis einai tēn hyper pasan kai aphairesin kai thesin." Se ha dicho que estas palabras de Dionisio "contradicen directamente" la lógica de Aristóteles (Pseudo-Dionysius. The Complete Works, p. 136; Aristóteles: 17a33), pero equivocadamente, pues lo que se afirma de Dios como aitia, causa de todas las cosas creadas, se niega de Dios como hyperousē, "supersiendo" sobre todas las cosas.

${ }^{28}$ Ibid., cap. 5: "Oute estin autēs [aitias] katholou thesis, oute aphairesis, alla tōn met' autēn tas theseis kai aphareseis poiountes, autēn oute tithemen oute aphairoumen, epei kai hyper pasan thesin estin hē pantelēs kai heniaia tōn pantōn aitia, kai hyper pasan aphairesin hē hyperochē tou pantōn haplōs apolelumenou kai epekeina tōn holōn.” 
$\varphi$

thesis: kataphasis

afirmación: la vía positiva

$\sim$ “ $\varphi$ "

(antítesis) aphairesis: apophasis

negación: la vía negativa

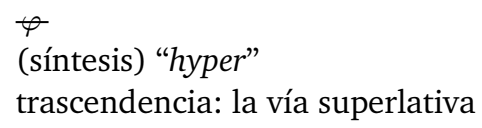

Así, esta dialéctica, puesto que en ella se niega (en distintos sentidos) no sólo la afirmación, sino la negación misma, a la larga no resulta "apofática". El propósito de Dionisio, evidentemente, no es enredarse en las negaciones antitéticas, sino subir "hyper", encima, más allá tanto de la kataphasis como de la apophasis. La vía superlativa no es agnosticismo.

\section{La lógica mística}

Cuando leemos atentamente los textos de San Juan de la Cruz, encontramos una paradoja. Se recordará que en el caso de las ballenas se trataba de la desambiguación. La primera noción de "ballena" era ambigua y general, y las nociones en la antítesis y síntesis son más definidas y particulares, a pesar de que la referencia en las tres proposiciones es igual (denotan las ballenas). En tales procesos cognoscitivos, pues, una noción relativamente confusa y general cede a nociones más claras, distintas y particulares.

El caso de Juan de la Cruz es distinto, pues parece trastrocar el proceso. Por cierto, una thesis $(\varphi)$ sería más oscura que su aphairesis (la negación " $\varphi$ "). Sin embargo la thesis no es más oscura que la síntesis $(\varphi)$, donde las "noticias e inteligencias" son "confusas, oscuras y generales". Pero no hay contradicciones aquí; el acercamiento al misterio es lógico.

El ejemplo de Bonhoeffer (y los otros filósofos comentados) también es distinto. El primer darse es ambiguo en comparación con el darse entrecomillado (no tienen la misma referencia). Sin embargo, el darse tachado será vago hasta que Bonhoeffer explique por qué él tiene el derecho a afirmar el darse correcto de Dios.

Mas hay otra dimensión aquí. San Pablo así ve su "llamamiento" como atleta de Cristo: 
Yo no pretendo haberlo alcanzado;

digo solamente esto:

olvidando lo que queda atrás, prosigo

y lanzándome a lo que está delante,

al skopos (a la meta),

al brabeion (al premio)... ${ }^{29}$

Pero para Pablo este skopos es, a fin de cuentas, escatológico. Juan de la Cruz refiere las últimas estrofas de su Cántico espiritual, más allá de las tres etapas de la maduración espiritual, al "estado beatífico, que sólo ya el alma en aquel estado perfecto pretende". ${ }^{30}$ Para estos místicos, pues, el estado de cosas sintético $(\varphi)$ incluye el brabeion, culmina en él. Según la dialéctica de Santo Tomás que citamos antes, si bien "en el camino" no conocemos la esencia divina, se recibirá el don de la comprensión "consumado en la patria": la visión

perfecta, por la cual se ve la esencia de Dios-

pero sin nunca "alcanzarla" por completo. ${ }^{31}$

El misterio, pues, el sod de las Escrituras judías, no es un secreto para ser guardado, sino para ser revelado. La palabra final no es apophasis, sino apokalypsis, epiphania. Dostoievski, como recordamos, escribió que si la verdad realmente (subraya la palabra) estuviera fuera de Cristo, se quedaría con Cristo y abandonaría la verdad. Escuchemos ahora al maestro Eckhart, el místico del Rhin:

¿Qué es la verdad?

La verdad es tan noble, que si Dios pudiera apartarse de la verdad,

${ }^{29}$ Filipenses 3:13-14: "kata skopon diōkō eis to brabeion tēs anō klēseōs tou Theou en Christō Iēsou".

${ }^{30}$ Cántico espiritual, B, "Argumento", 2.

${ }^{31}$ Summa Theologica, 2-2:8:7. Tomás creyó que la fe es expresable en proposiciones articuladas, pero la fe, junto con la esperanza, ha de ceder a esta "visión", ya no como "enunciado", sino "todo junto" en una "simple inteligencia": "visio illa erit non per modum enuntiabilis, sed per modum simplicis intelligentiae" (Summa Theologica, 2-2:1:2 ad 3; también 2-2:1:1-2 y 1:12:3,7,8,10). Véanse Redmond, "A Logic of Religious Faith and Development" y "Eine Logik der religiösen Hoffnung". 
yo querría adherirme a la verdad, y querría abandonar a Dios. ${ }^{32}$

Pues si no es verdad, ¿para qué perder el tiempo?

Hay, pues, afirmación-negación como también negación de la afirmación-negación; hay razón y fe, lógica y misterio, logos y el Logos. Pero icuidado! San Juan de la Cruz escribió, mientras "se huelga de conocer a Dios por fe":

Qué bien sé yo la fonte

que mana y corre-

aunque es de noche. ${ }^{33}$

\section{BIBLIOGRAFÍA}

Anónimo, The Cloud of Unknowing, Paulist Press, Nueva York, 1981.

Bloch, E., Das Prinzip Hoffnung, t. 5 de las obras completas, Suhrkamp, Fráncfort del Meno, 1985.

Bonhoeffer, D., Akt und Sein, Transzendentalphilosophie und Ontologie in der systematischen Theologie, 2a. ed., Chr. Kaiser Verlag, Munich, 1956.

Buenaventura, Santo, Itinerarium mentis in Deum, trad. P. Boehner, Saint Bonaventure University, Saint Bonaventure, NY, 1956.

Calcagno, A., "God and the Caducity of Being: Jean-Luc Marion and Edith Stein on Thinking God" [en línea], חAI $\Delta$ EIA, Filosofía de la Religión, The Paideia Project On-Line, disponible en: <http://www.bu.edu/wcp/Papers/Reli/Reli Calc.htm>.

Comte-Sponville, A., L'Esprit de l'athéisme, Albin Michel, París, 2006.

Dionisio el Areopagita, Peri tēs mystikès theologias, en Pseudo-Dionysius. The Complete Works, trad. C. Luibheid y J. Rorem, Paulist Press, Nueva York, 1978, pp. 133-142.

Dostoievski, F, Pis'ma, Gos. izd-vo, Moscú, 1928.

Eckhart, "Meister", Die deutschen und lateinischen Werke. Hrsg. im Auftrage der Deutschen Forschungsgemeinschaft, ed. J. Quint, Kohlhammer, Stuttgart, 1936-.

Eliot, T.S., The Family Reunion. A Play, Harcourt, Brace and Company, Nueva York, 1939.

Fowler, J.W., Stages of Faith, Harper and Row, San Francisco, 1981.

32 "Waz ist diu wârheit? Wârheit ist als edel, waere, daz sich got gekêren möchte von der wârheit, ich wölte mich an die wârheit heften und wölte got lâzen", sermón 26, "Mulier, venit hora," Predigten, 2:1-4, ed. Quint (Stuttgart, 1968), pp. 2425.

${ }^{33}$ Cantar del alma.

Diánoia, vol. LIV, no. 62 (mayo 2009). 
Freud, S., Die Zukunft einer Illusion, Internationaler Psychoanalytischer Verlag, Viena, 1927.

Heidegger, M., "Die onto-theo-logische Verfassung der Metaphysik", en Identität und Differenz, 2a. ed., Pfullingen, Neske, 1957. [Versión en castellano: "La constitución onto-teo-lógica de la metafísica", trad. Helena Cortés y Arturo Leyte, en Identidad y diferencia, ed. bilingüe, Anthropos, Barcelona, 1988, pp. 98-157.]

Hintikka, J., Knowledge and Belief. An Introduction to the Logic of the Two Notions, Cornell University Press, Ithaca, NY, 1962.

Juan de la Cruz, Santo, Cantar del Alma que se huelga de conocer a Dios por fe, en Obras completas, pp. 11-13.

—_ Cántico espiritual, en Obras completas, pp. 423-734.

- Noche oscura, en Obras completas, pp. 317-422.

—, Obras completas, 11a. ed., Biblioteca de Autores Cristianos, Madrid, 1982.

—_ Subida del Monte Carmelo, en Obras completas, pp. 79-316.

Kerr, F., After Aquinas. Versions of Thomism, Blackwell, Oxford, 2002.

Leibniz, G.W., Die Philosophische Schriften von Gottfried Wilhelm Leibniz, Olms Verlagsbuchhandlung, Hildesheim, 1960-1961.

Marion, J.-L., Dieu sans l'être. Hors-texte, Arthème Fayard, París, 1982, y Quadrige, París, 1991; 2a. ed. corregida y aumentada, 2002; y versión en inglés: God without Being. Hors-texte, trad. T.A. Carlson, The Chicago University Press, Chicago, 1991.

Morrow, D.J., "Aquinas According to the Horizon of Distance: Jean-Luc Marion's Phenomenological Reading of Thomistic Analogy", inédito.

—-, "Aquinas, Marion, Analogy, and Esse: A Phenomenology of the Divine Names?", International Philosophical Quarterly, vol. 46, no. 1, 2006, pp. 2542.

Pascal, B., Pensées, R. Laffont, París, 1960.

Redmond, W., "A Logic of Religious Faith and Development", The Rationality of Theism, ed. A. García de la Sienra, Rodopi, Amsterdam, 2000, pp. 35-59.

—_, "Eine Logik der religiösen Hoffnung", Theologie und Glaube, no. 4, 1992, pp. 414-438.

Stein, E., Erkenntnis und Glaube, vol. 15 de Edith Steins Werke, Friburgo/Basilea/Viena, Herder, 1993; versión en inglés: Knowledge and Faith, trad. W. Redmond, Institute of Carmelite Studies, Washington, 2000.

Tomás de Aquino, Santo, De ente et essentia opusculum. [Versión en castellano: El ente y la esencia, trad., prólogo y notas de Manuel Fuentes Benot, Editorial Aguilar Argentina S. A. de Ediciones, Buenos Aires, 1954.]

_ De ente et essentia, en Los fundamentos de la ontología tomista. El tratado De ente et essentia, edición bilingüe, ed. D. Lorenz Daiber, Ediciones Universitarias de Valparaíso, Valparaíso, 2005.

—_ Summa Theologica, 3a. ed., edición bilingüe, trad. J.M. Pla Castellano y Francisco Barbado Viejo, Biblioteca de Autores Cristianos, Madrid, 1964. 
Tugwell, S. (ed. y trad.), Albert and Thomas. Selected Writings, Paulist Press, Nueva York, 1998.

Wittgenstein, L., "Logisch-philosophische Abhandlung", Annalen der Naturphilosophie, vol. 14, 1921, pp. 185-262.

Wolin, R., "Heidegger Made Kosher", The Nation, vol. 282, no. 7, 20 de febrero de 2006, pp. 23-30.

Recibido el 6 de diciembre de 2007; revisado el 27 de julio de 2008; aceptado el 3 de septiembre de 2008. 